\title{
Targeting the Hedgehog signaling pathway in cancer: beyond Smoothened
}

\author{
Annelies Gonnissen ${ }^{1}$, Sofie Isebaert ${ }^{1}$ and Karin Haustermans ${ }^{1,2}$ \\ ${ }^{1}$ University of Leuven (KU Leuven), Department of Oncology, Laboratory of Experimental Radiotherapy, Leuven, Belgium \\ ${ }^{2}$ University Hospitals Leuven, Department of Radiation Oncology, Leuven, Belgium \\ Correspondence to: Annelies Gonnissen, email: annelies.gonnissen@med.kuleuven.be \\ Keywords: Hedgehog pathway, GLI transcription factors, GANT61, DNA repair, apoptosis \\ Received: March 24, $2015 \quad$ Accepted: May 13, $2015 \quad$ Published: May 22, 2015
}

This is an open-access article distributed under the terms of the Creative Commons Attribution License, which permits unrestricted use, distribution, and reproduction in any medium, provided the original author and source are credited.

\section{ABSTRACT}

An essential role for Hedgehog ( $\mathrm{Hh}$ ) signaling in human cancer has been established beyond doubt. At present, targeting Hh signaling has mainly been investigated with SMO inhibitors. Unfortunately, resistance against currently used SMO inhibitors has already been observed in basal cell carcinoma (BCC) patients. Therefore, the use of $\mathrm{Hh}$ inhibitors targeting the signaling cascade more downstream of SMO could represent a more promising strategy. Furthermore, besides the classical canonical way of Hh signaling activation, non-canonical activation of the GLI transcription factors by multiple important signaling pathways (e.g. MAPK, PI3K, TGF $\beta$ ) has also been described, pinpointing the importance of targeting the transcription factors GLI1/2. The most promising agent in this context is probably the GLI1/ 2 inhibitor GANT61 which has been investigated preclinically in numerous tumor types in the last few years. In this review, the emerging role of Hh signaling in cancer is critically evaluated focusing on the potential of targeting Hh signaling more downstream of SMO, i.e. at the level of the GLI transcription factors. Furthermore, the working mechanism and therapeutic potential of the most extensively studied GLI inhibitor in human cancer, i.e. GANT61, is discussed in detail. In conclusion, GANT61 appears to be highly effective against human cancer cells and in xenograft mouse models, targeting almost all of the classical hallmarks of cancer and could hence represent a promising treatment option for human cancer.

\section{INTRODUCTION}

In this review, the emerging role of Hedgehog $(\mathrm{Hh})$ signaling in cancer is critically evaluated focusing on the potential of targeting Hh signaling as an anticancer strategy. More specifically, the relevance of targeting $\mathrm{Hh}$ signaling more downstream of Smoothened (SMO), i.e. at the level of the glioma-associated oncogene homolog (GLI) transcription factors, is highlighted. Furthermore, the working mechanism and therapeutic potential of the most extensively studied GLI-inhibitor in human cancer, i.e. GANT61, is discussed in detail.
The Hh signaling pathway

The Hh pathway, one of the major developmental pathways, is a very complex signaling network comprising both canonical and non-canonical signaling. Activation of canonical $\mathrm{Hh}$ signaling occurs when one of the ligands, i.e. Sonic (Shh), Desert (Dhh) or Indian (Ihh) Hedgehog binds to its receptor Patched (PTCH). This relieves the repression of SMO by $\mathrm{PTCH}$ and results in the accumulation of SMO in the primary cilium. Activated Smo in turn, facilitates the activation of the GLI transcription factors which will translocate to the nucleus and promote transcription of the Hh target genes. The GLI family of transcription factors consists of three different proteins (GLI1, GLI2 and GLI3), of which only GLI1 is 
an exclusively full-length transcriptional activator. GLI3 and, to a lesser extent, GLI2 can be partially processed into truncated repressor forms $[1,2]$. The activation of the GLI transcription factors is controlled by Suppressor of Fused (SUFU) which is a key negative regulator of Hh signaling activity. In the absence of ligand binding, SUFU will directly bind the GLI proteins and inhibit their translocation to the nucleus and thus prevent pathway activation [3]. The anchorage of the GLI proteins in the cytoplasm by SUFU will facilitate processing and/or degradation of the GLI proteins and thereby inhibit Hh signaling [4]. To date, numerous target genes have been described, which are involved in feedback mechanisms (e.g. HHIP, PTCH1, GLI1), cell cycle regulation (e.g. CYCLIN D1/2), proliferation (e.g. PDGFR, MYC) apoptosis (e.g. BCL2), angiogenesis (e.g. $V E G F$, $A N G 1 / 2$ ), epithelial-mesenchymal transition (EMT; e.g. $M M P 9, S N A I L)$ and self-renewal (e.g. NANOG, SOX2) $[5,6]$, representing a broad spectrum of mechanisms by which the Hh signaling pathway can be involved in carcinogenesis.

Hh signaling can also be activated by non-canonical signaling. Non-canonical Hh activation has been defined as either ligand-independent $\mathrm{Hh}$ activation originating from PTCH (Type I) and/or SMO (Type II), but independent of GLI-mediated transcription [7,8] or through direct stimulation of the GLI transcription factors, independent of PTCH/SMO signaling $[6,9,10]$. Multiple important oncogenic pathways (e.g. PI3K, MAPK, Wnt, NF- $\kappa \mathrm{B}$ and TGF $\beta$ ) have been shown to activate Hh signaling. More specifically, PI3K, MAPK and TGF $\beta$ signaling induce their effect, at least partially, through the activation of the GLI1/2 transcription factors [11]. Moreover, crosstalk with tumor suppressor genes (e.g. P53, PTEN) has also been demonstrated $[6,9,11]$, making this pathway a very interesting target for cancer therapy.

In recent years, the $\mathrm{Hh}$ signaling pathway has shown to be an essential key player in tumor initiation and/or progression to more advanced tumor stages $[1,2$, $12,13]$. At the moment, inappropriate $\mathrm{Hh}$ signaling has been demonstrated in more than $30 \%$ of human cancers, including basal cell carcinoma (BCC), medulloblastoma (MB), melanoma, breast, prostate, lung, pancreatic, cervical and ovarian cancer [14]. Inappropriate $\mathrm{Hh}$ signaling has been ascribed to either ligand-dependent, i.e. autocrine and/or paracrine signaling, or ligand independent tumor cell intrinsic pathway activation due to loss-of-function mutations in $P T C H$ or $S U F U$ and gain-offunction mutations in $S H H, S M O$ or $G L I 1 / 2$ [5, 15]. The latter has mainly been observed in BCC and MB.

\section{SMO inhibitors}

The last decades, major progress has been made in the development of small molecules specifically inhibiting the Hh signaling pathway. Initially, pharmaceutical companies mainly focused on targeting SMO. Several SMO inhibitors are currently being tested in clinical trials for the treatment of multiple types of cancer. The most extensively studied SMO inhibitor is cyclopamine [16], a naturally occurring substance derived from the plant Veratrum californicum, which demonstrated high efficiency in preclinical studies, but failed clinical development due to poor pharmacokinetic characteristics (highly insoluble in water, poor chemical stability in acidic conditions), low potency and associated toxicity [17]. This led to the development of many small molecule Hh pathway modulators with improved potency and druggability, e.g. vismodegib (GDC-0449), IPI-926, sonidegib (LDE-225), BMS-833923, PF-04449913 and LY2940680. These SMO inhibitors seem to be highly efficient in patients with tumors harboring activating mutations in the $\mathrm{Hh}$ pathway, i.e. BCC and MB. In 2012, vismodegib has been approved for the treatment of advanced BCC on the basis of a phase II clinical trial with response rates of $30 \%$ and $43 \%$ in metastatic BCC and locally advanced BCC respectively [18]. Currently, sonidegib, BMS-833923 and IPI-926 have also proven efficacy in BCC and MB [19, 20]. At present, (clinical) investigations are ongoing to evaluate their efficacy in ligand-dependent $\mathrm{Hh}$ activated cancer types. However, these solid tumor types demonstrated little or no responsiveness in early phase clinical trials [21].

Regrettably, acquired resistance against vismodegib has already been reported in patients with advanced BCC and MB [22, 23]. In a study by Chang et al. evaluating re-growth in patients with BCC treated with continuous vismodegib, 6 out of 28 patients patients developed at least one tumor regrowth (mean time 56.4 weeks) while on the drug treatment [24]. Acquired resistance to SMO inhibition has been linked to distinct mechanisms, such as mutations in SMO (e.g., D473H) [25], amplification of the downstream transcription factor GLI2 [26] or upregulation of synergistic signals such as PI3K signaling [27].

Possible solutions for these patients include (1) second-generation SMO inhibitors with a different mechanism of action that are still effective in vismodegibresistant patients (e.g. HhAntag), (2) Hh pathway inhibitors more downstream of SMO (e.g. GANT58, GANT61) and (3) combination strategies with other molecular targeted therapies (e.g. PI3K, EGFR inhibitors), ionizing radiation or chemotherapy $[13,28]$.

The most promising targets within the Hh signaling pathway are by far the GLI transcription factors. First, these molecules are most downstream of the signaling pathway. Therefore, small molecules targeting the GLI transcription factors will still be effective in tumors harboring mutations in SMO or even more downstream of SMO (e.g. SUFU). Second, non-canonical activation of the GLI proteins occurs by several important oncogenic pathways. The fact that the GLI transcription factors are 
described as, at least partial, effectors of these oncogenic pathways highlights the potential therapeutic benefit of targeting these molecules.

\section{GLI1/2 AS EMERGING TARGETS FOR CANCER THERAPY}

\section{Gli activation in tumors}

The first indication of involvement of Hh signaling in cancer came from a study by Kinzler et al., already in 1987, identifying a gene that was more than 50 -fold amplified in malignant glioma. This gene was then named after the tumor, i.e. glioma-associated oncogene homolog 1 (GLI1) [29]. Currently, overexpression of GLI1 has been described in multiple other tumor types such as MB [30], rhabdomyosarcoma [31, 32], prostate [33, 34], biliary [35], breast [36-38], lung [39], colon [40, 41] and bladder [42] cancer. Moreover, higher GLI1 expression is associated with more advanced (and metastatic) tumors $[33,35,38]$.

Several studies have also demonstrated the prognostic value of several Hh proteins in cancer patients. Protein expression of SHH, PTCH and GLI1 were all independent prognostic factors for both disease-free survival and overall survival in patients with colon cancer [40] and bladder cancer [42]. Fan et al. also demonstrated that low GLI1 expression correlates with a longer survival in patients with oral squamous cell carcinoma (SCC) [43]. Another study by ten Haaf et al. showed that GLI1 expression in breast cancer is associated with an unfavorable overall survival [37]. Furthermore, Chung et al. have observed that nuclear GLI1 expression is associated with metastasis and poor survival in patients with head-and-neck SCC after radiation treatment [44].

Since GLI1 is both a transcription factor and a target gene of Hh signaling, GLI1 expression is often considered as a measure for Hh signaling activity. Overexpression of GLI1 can be the result of either ligand-dependent or ligand-independent cell intrinsic $\mathrm{Hh}$ activation. Mutations at any level of the signaling pathway (e.g. PTCH1, SMO, SUFU) will result in an increased expression of GLI1. Amplification of the GLI transcription factors has only been described in a subset of tumor types, such as glioblastoma, BCC and bladder cancer [29, 45, 46]

\section{Targeting Hh signaling at the level of GLI1/2}

Currently, only a few GLI inhibitors have been developed, whereas dozens of SMO inhibitors are on the market of which several are under clinical investigation. Both natural and synthetic GLI inhibitors have been described [47]. Triazole itraconazole is a natural antifungal agent that inhibits $\mathrm{Hh}$ signaling downstream of
PTCH, but entails a different mechanism as known SMO inhibitors [48]. The mechanism of action of this compound is not completely understood, but is thought to be due to inhibition of GLI-mediated transcription [49]. Other natural compounds able to inhibit GLI transcription were identified in a large-scale screen for inhibitors of GLI transcription. Five compounds were shown to effectively inhibit both GLI1- and GLI2-mediated transcription, i.e. staurosporinone, zerumbone, arcyriaflavin C, physalin B and physalin F [50]. Several synthetic agents have been described to specifically target the GLI transcription factors, each with a different mode of action, e.g. HPI1-4, ATO, GANT58, GANT61, GlaB, JQ1 and I-BET151.

Targeting Hh signaling at the level of GLI1/2 can be classified in four categories, as shown in Figure 1: 1) inhibition of GLI processing and its trafficking (posttranslational modifications), 2) inhibition of GLI-DNA binding, 3) inhibition of transcriptional output, and 4) indirect inhibition.

\section{Inhibition of GLI processing and trafficking}

The primary cilium plays an essential role in the trafficking and posttranslational processing of the GLI transcription factors. Appropriate ciliary function is important for processing of both the repressor and activator forms of GLI proteins. As depicted in Figure 1, in the absence of Hh ligand, SMO is retained from the primary cilium and therefore not able to activate the GLI transcription factors. In this state, SUFU will bind the GLI transcription factors and retain the GLI proteins to the cytoplasm, thereby facilitating GLI processing. The sequential phosphorylation of the GLI proteins by protein kinase A (PKA), casein kinase 1 (CK1) and glycogen synthase kinase $3 \beta$ (GSK3 $\beta$ ) targets the proteins to the proteasome for (partial) degradation. GLI inhibition can occur at different levels in the activation process of the GLI transcription factors. Increased proteosomal processing to their repressor forms, decreased processing into transcriptional activators and reduced trafficking of the GLI proteins are several mechanisms that will result in inhibition of GLI transcriptional activity. Unlike GLI2 and GLI3, GLI1 is not cleaved to a repressor form, but will be degraded by the ubiquitin-proteasome system (UPS). In general, GLI1 protein levels are strictly controlled to allow proper target gene transcription and prevent inappropriate signaling activity. A study by Huntzicker et al has shown that degradation of the GLI1 proteins occurs quite rapidly and is controlled by two independent destruction signals (degron $\mathrm{D}_{\mathrm{C}}$ and degron $\mathrm{D}_{\mathrm{N}}$ ). Mutations in one or both degrons resulted in the accumulation of GLI1 proteins, which was significantly correlated with an increased transcriptional activity, thereby contributing to carcinogenesis [51]. Targeting the accumulation of the GLI proteins might therefore also represent a promising anticancer strategy.

A study by Hyman et al. describes four Hedgehog 
pathway inhibitors (HPIs) that are able to modulate GLI activity each with a unique mechanism of action. HPI-1 has been shown to increase the GLI repressor level, likely through posttranslational processing (PKA phosphorylation). HPI-2 and HPI-3 appeared to interfere with the processing of GLI2 to its transcriptional activator form. HPI-4 seemed to act on ciliogenesis, thereby inhibiting the processing of GLI into their activator form [52].

Recently, a novel role has been ascribed to the Tolllike receptor-7/8 (TLR7/8) agonist, imiquimod (IMQ), which has been approved for the treatment of BCC. IMQ negatively regulates $\mathrm{Hh}$ signaling in a PKA-dependent manner. More specifically, IMQ binds to adenosine receptors (ADORAs) which activate PKA, resulting in the phosphorylation and subsequent degradation of GLI1 $[53,54]$. In this context, other molecules that stimulate ADORA/PKA signaling could represent a new class of anticancer therapy by repressing Hh signaling.

Arsenic trioxide (ATO), currently used for the treatment of acute promyelocytic leukemia (APL), has been demonstrated as a potent and specific inhibitor of Hh signaling. Kim et al. demonstrated that ATO inhibits GLI2 trafficking in and out the primary cilium, which is necessary for appropriate GLI2 activation. This ultimately results in a blockage of GLI2 accumulation in the primary cilium and subsequently destabilization of GLI2, which leads to a decreased level of GLI2 after long term treatment with ATO [55].

\section{Inhibition through direct binding to GLI proteins}

The GLI proteins belong to the family of zinc finger proteins, one of the most important families of DNA-binding proteins. The GLI protein consists of five zinc finger proteins of which only finger 1 does not make contact with the DNA. Zinc fingers 2 to 5 bind the major

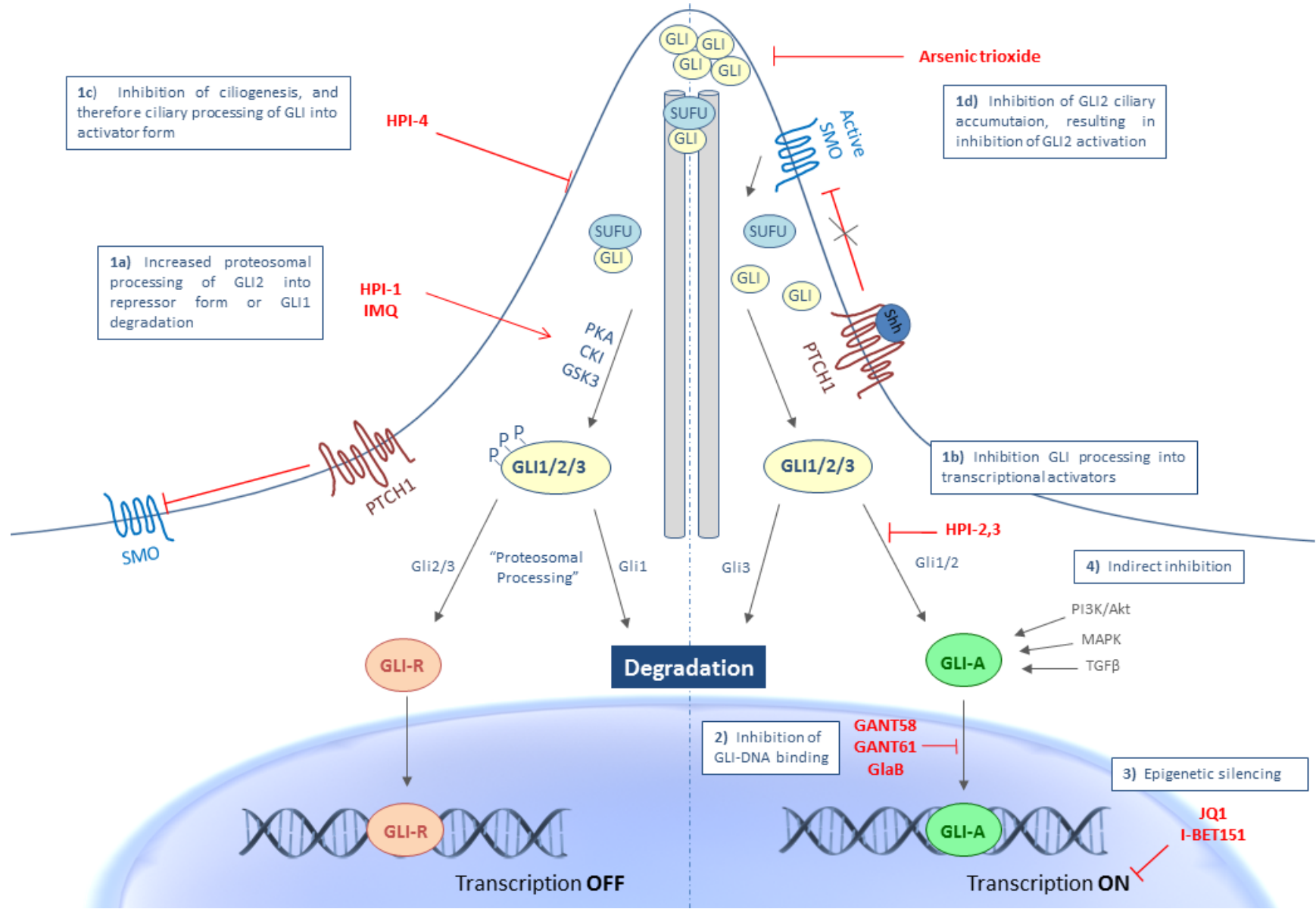

Figure 1: Targeting Hh signaling at the level of the GLI transcription factors. GLI inhibition can occur at different levels in the activation process of GLI transcriptional output: 1a. Increased proteosomal processing of GLI2 into repressor form or GLI1 degradation with HPI-1 or IMQ. 1b. Inhibition of GLI processing into its activator form by HPI-2/3, 1c. Inhibition of ciliogenesis and therefore processing into the activator form with HPI-4, 1d. Inhibition of GLI2 ciliary accumulation and thus activation of of GLI2 by ATO. 2. Inhibition at the level of GLI-DNA binding through GANT58, GANT61 or GlaB, 3. Through epigenetic silencing with JQ1 or I-BET151 and 4. Through indirect inhibition of non-canonical signaling pathways known to activate the GLI transcription factors. Abbreviations: CKI, casein kinase 1; GANT, Gli-ANTagonist; GlaB, Glabrescione; GLI, Glioma-associated oncogene homologue; GLI-A, activator form of GLI; GLI-R, repressor form of GLI; GSK3 $\beta$, glycogen synthase kinase $3 \beta$; HPI, Hedgehog Pathway Inhibitor; IMQ, imiquimod; P, phosphate; PKA, protein kinase A; PTCH1, patched 1; SHH, sonic hedgehog; SMO, smoothened; SUFU, suppressor of fused 
groove and wrap around the DNA helix. More specifically, zinc finger 2 and 3 are believed to mainly bind the DNA backbone whereas finger 4 and 5 directly make contact with the DNA base pairs $[56,57]$.

The first small molecules that were identified as $\mathrm{Hh}$ signaling inhibitors at the level of the GLI transcription factors were GANT58 and GANT61 (Gli-ANTagonist) [58]. Agyeman et al. have demonstrated that GANT61 directly binds GLI1 in a groove between zinc finger 2 and 3 , which is not in the DNA binding region of GLI1, but this interaction does result in an inhibition of GLI-DNA binding and therefore GLI-mediated transcription [59]. The specific mechanism of action and therapeutic potential of GANT61 will be discussed in more detail below.

A recent study from Infante et al. describes a new GLI inhibitor Glabrescione B (GlaB) which also interferes with the interaction between GLI1 and DNA, but at the interface between zinc fingers 4 and 5, which are responsible for the interaction between GLI1-DNA [60].

\section{Inhibition of Hh transcriptional output through epigenetic silencing}

Two recent studies identified bromodomain and extra terminal (BET) proteins, and more specifically BRD4 proteins, as critical epigenetic regulators of $\mathrm{Hh}$ transcriptional output. BRD4 directly binds GLI1 and GLI2 promoters, thereby epigenetically regulating GLI transcription. In the first study, Tang et al. described the potential of JQ1, a BRD4 inhibitor, as an effective agent against $\mathrm{Hh}$ activity. Tumor growth was significantly attenuated in several tumor models with constitutive Hh pathway activation, even with resistance to SMO inhibitors [61]. In the second study, Long et al. performed a small molecule screen for epigenetic modulators against Hh signaling activity and identified the BET inhibitor, I-BET151 to effectively attenuate Hh activity, also through BRD4 inhibition. Treatment with I-BET151 also led to a decrease in tumor growth in an Hh-driven MB mouse model [62].

These studies provide evidence that targeting the BET bromodomain proteins, especially BRD4 inhibitors, could represent a promising future strategy to target Hh-driven tumors and could be effective in tumor cells harboring mutations in SMO or even more downstream of SMO. However, in addition to its antitumor effects, JQ1 has also shown to have an effect on several other important physiological and pathological processes like spermatogenesis, inflammation and cardiovascular disease [63]. Therefore, more investigation into the exact role of BRD4 inhibition in human cancer and potential toxicities due to multiple targeting is needed.

\section{Indirect inhibition of GLI transcription factors}

As stated above, the GLI transcription factors are modulated by several important oncogenic pathways, such as PI3K, TGF $\beta$ and MAPK signaling [10]. Consequently, targeted agents against these pathways could also be regarded as "indirect" inhibitors of Hh signaling.

Furthermore, one potential mechanism of resistance against SMO inhibitors has been ascribed to an increased activity of PI3K signaling. Simultaneous inhibition of both pathways has been demonstrated to significantly delay the development of resistance [27]. Moreover, a study by Wang et al. describes a link between mTOR signaling and GLI1 activity. Activated mTOR signaling resulted in an increased transcriptional activity and oncogenic function of GLI1. Simultaneous inhibition of mTOR (RAD-001) and Hh signaling (GDC-0449) resulted in an additional tumor growth inhibition in vivo in an esophageal xenograft mouse model compared to either single drug treatment [64].

\section{GANT61}

In a cell-based screen for small molecule inhibitors of GLI-mediated transcription, Lauth et al. discovered GANT58 and GANT61 to selectively inhibit both GLI1 and GLI2-mediated gene transactivation. Both inhibitors caused significant inhibition of tumor growth, but GANT61 was shown to be more efficient [58]. This prompted further investigation of this agent and resulted in the publication of several preclinical studies performed in numerous cancer types, including rhabdomyosarcoma, neuroblastoma, leukemia, colon, pancreas, prostate, cervix, melanoma, lung, head-and-neck and gastric cancer. In this part of the review, we will summarize the findings of these studies, especially regarding the different target sites and therapeutic potential of GANT61 in human cancer to gain more insight into the exact working mechanisms of this agent.

The specificity of GANT61 to inhibit GLI-mediated transcription has been shown in multiple studies and, as stated above, was first described by Lauth et al. [58]. GANT61 has been demonstrated to decrease both gene and protein expression of the target genes GLI1 and PTCH1 and to reduce also the transcriptional output using GLI reporter assays in multiple cell types [58, 65-68].

Until recently, little was known about the exact working mechanism of GANT61. Then, Agyeman et al. investigated the mode of binding of GANT61 to the GLI transcription factors. By means of computational modeling, the authors showed that the biological activity of GANT61 is through direct binding to GLI1, in close proximity to, but independent of the DNA binding region of GLI1. GANT61 binds GLI1 in a groove between zinc finger 2 and 3 and has binding sites at amino acids E119 (1H bond) and E167 (2H bonds). Mutations in these two binding sites resulted in a significant inhibition of binding between GANT61 and GLI1, confirming the interaction between both molecules. Moreover, most of the amino acid residues within $3.5 \AA$ of GANT61 appeared to be conserved between GLI1 and GLI2, which could explain the inhibitory effect of GANT61 also on GLI2-mediated 
transcription [59].

The cytotoxic effect of GANT61 has been investigated in numerous cancer cell types, with $\mathrm{IC}_{50}$ values ranging from $5 \mu \mathrm{M}-15 \mu \mathrm{M}$ after $48 \mathrm{~h}-72 \mathrm{~h}$ in most cancer cell lines (Table 1). In cell lines known to be independent of GLI signaling, higher concentrations ranging up to $90 \mu \mathrm{M}$ were needed to cause any significant cytotoxicity, probably rather due to nonspecific toxicity of the high dose of drug or diluent (i.e. ethanol or dimethylsulfoxide (DMSO)).

\section{Working mechanisms of GANT61 in human cancer cells}

The next part of this review summarizes the main effects of GANT61 treatment, illustrating that GANT61 targets many of the "classical hallmarks of cancer", such as cell viability, proliferation, apoptosis, DNA damage repair, epithelial-mesenchymal transition (EMT), autophagy, cancer stem cells and immune response (Figure 2).

\section{Limitless replicative potential}

An unlimited replicative potential is one of the most important hallmarks of cancer. Normal somatic cells have a limited potential to replicate due to the shortening of the telomeres, which are heterochromatic structures located at the ends of the chromosome and mainly function to protect the chromosomes from recombination, degradation and end-to-end fusion [69]. With every DNA replication cycle, the telomeres are shortened since DNA polymerase is unable to fully copy the ends of telomeric DNA in the absence of a template strand ('end-replication effect'). When the telomeres become critically shortened, they fail to protect the chromosomal ends resulting in irreversible growth arrest and replicative senescence. Telomerase prohibits this telomere shortening by catalyzing de novo synthesis of telomeric DNA after cell division and aberrant activation of telomerase has been implicated in carcinogenesis [70]. The expression level of human telomerase reverse transcriptase ( $h T E R T)$, a catalytic subunit bearing the enzymatic activity of telomerase, is considered the rate-limiting determinant of human telomerase activity [71]. Many factors have been implicated in the regulation of $h T E R T$ in cancer and normal cells, including Wnt signaling, c-Myc, HIF1 and p53 [72-75]. In a recent paper, Mazumdar et al. have shown that Hh signaling transcriptionally regulates hTERT in colon, prostate and brain cancer cells, but not in the non-malignant $293 \mathrm{~T}$ cells. Inhibition with GANT61 reduced hTERT protein and mRNA expression by preventing the binding of GLI1/2 with the hTERT promotor in human colon cells [76]. Thus, GANT61 can decrease the proliferative potential of cancer cells through interference with hTERT activity. Another mechanism by which GANT61 inhibits proliferation is by its effects on
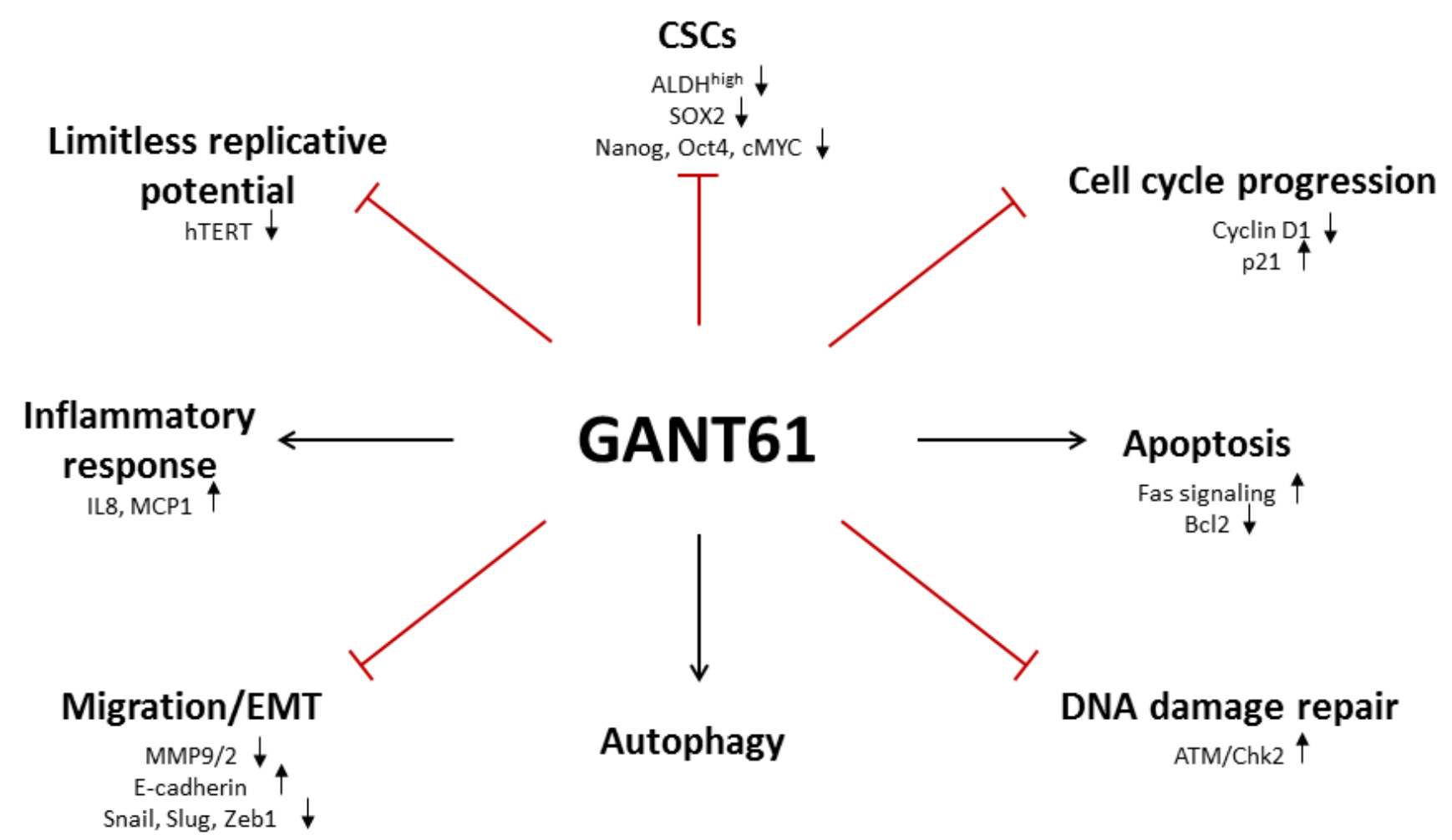

Figure 2: Schematic overview of different GANT61 target sites. Inhibition of the GLI transcription factors with GANT61 targets many of the "classical hallmarks of cancer", such as cell viability, proliferation, apoptosis, DNA damage repair, epithelial-mesenchymal transition (EMT), autophagy, cancer stem cells and immune response. 
Table 1: Overview of $\mathrm{IC}_{50}$ values of GANT61 in different tumor types

\begin{tabular}{|c|c|c|c|c|c|}
\hline Tumor type & Cell line & IC $_{50}$ value & $\begin{array}{c}\text { Treatment } \\
\text { duration }\end{array}$ & Assay & Reference \\
\hline MEF & NIH $3 \mathrm{~T} 3$ & $5 \mu \mathrm{M}$ & $48 \mathrm{~h}$ & GLI reporter assay & 58 \\
\hline Colon & $\begin{array}{c}\text { HT29 } \\
\text { HCT } 116 \\
\text { SW480 } \\
\text { VRC5/c1 } \\
\text { GC3/c1 }\end{array}$ & $5-15 \mu \mathrm{M}$ & $72 \mathrm{~h}$ & Clonogenic assay & 81 \\
\hline Neuroblastoma & $\begin{array}{c}\text { SK-N-AS } \\
\text { SK-N-DZ } \\
\text { IMR-32 } \\
\text { SK-NBE(2) } \\
\text { SH-SY5Y } \\
\text { SK-N-FI } \\
\end{array}$ & $5,28-12,4 \mu \mathrm{M}$ & $72 \mathrm{~h}$ & $\begin{array}{l}\text { Fluorometric microculture } \\
\text { cytotoxicity assay (FMCA) }\end{array}$ & 67 \\
\hline Cervix & $\begin{array}{c}\mathrm{HaCaT} \\
\mathrm{SiHa} \\
\mathrm{CasKi} \\
\mathrm{HeLa}\end{array}$ & $5-10 \mu \mathrm{M}$ & $48 \mathrm{~h}$ & BrdU ELISA kit & 94 \\
\hline Myeloid leukemia & $\begin{array}{c}\text { Kasumi-1 } \\
\text { K562 } \\
\text { HL60 } \\
\text { U937 }\end{array}$ & $<10 \mu \mathrm{M}-75 \mu \mathrm{M}$ & $48 \mathrm{~h}$ & WST assay & 107 \\
\hline Pancreas & Primary tumor & $10 \mu \mathrm{M} / 5 \mu \mathrm{M}$ & $48 \mathrm{~h} / 72 \mathrm{~h}$ & XTT assay & 68 \\
\hline Lung & $\begin{array}{c}\text { NCI-520 } \\
\text { NCI-H226 } \\
\text { SK-MES-1 } \\
\text { NCI-H2170 (GLI-negative) }\end{array}$ & $\begin{array}{c}5-10 \mu \mathrm{M} \\
\text { No effect }(>90 \mu \mathrm{M})\end{array}$ & $96 \mathrm{~h}$ & ApoLive-Glo Multiplex assay & 79 \\
\hline Pleural mesothelium & $\begin{array}{c}\mathrm{H} 2452 \\
\mathrm{H} 2373 \\
\mathrm{H} 513 \\
\mathrm{H} 2052 \\
\text { Gardner } \\
\text { Gates } \\
\text { H290 } \\
\text { REN } \\
\end{array}$ & $2.5-10 \mu \mathrm{M}$ & $96 \mathrm{~h}$ & MTT assay & 65 \\
\hline Biliary tract & $\begin{array}{c}\text { GBC } \\
\text { CCSW-1 } \\
\text { MzChA-1 }\end{array}$ & $<10 \mu \mathrm{M}$ & $72 \mathrm{~h}$ & Resazurin test & 35 \\
\hline Rhabdomyosarcoma & $\begin{array}{c}\text { RH30 } \\
\text { CW9019 } \\
\text { SMS-CTR } \\
\text { RD } \\
\text { A204 }\end{array}$ & $100-250 \mu \mathrm{M}$ & $24 \mathrm{~h}$ & MTT assay & 77 \\
\hline
\end{tabular}

cell cycle progression. Several independent studies have shown that GANT61 induces a G1 arrest, consistent with decreased protein levels of the Hh target gene Cyclin D, which is a driver for the progression from $\mathrm{G} 1$ to $\mathrm{S}$ phase $[67,77,78]$. Moreover, GANT61 induced the expression of p21, which also inhibits cell cycle progression $[76,77]$.

\section{Apoptosis}

Cytotoxicity of GANT61 has frequently been associated with increased cell death rather than a direct effect on cell proliferation. Inhibition of Hh signaling can cause apoptosis either through activation of Fas signaling or through decreasing protein levels of the anti-apoptotic $\mathrm{Bcl} 2$, which is one of the target genes of Hh signaling. Multiple independent studies have demonstrated that GANT61 induces cell death through both mechanisms. On the one hand, GANT61 induced Fas signaling, characterized by increased protein levels of Fas, cleaved caspase 3, cleaved PARP $[67,79,80]$ and death receptor 5 (DR5). PDGFR $\alpha$ levels were decreased after GANT61, which potentially contributed to the increase of Fas-mediated apoptosis, since PDGFR $\alpha$ regulates Fas expression $[68,81]$. On the other hand, GANT61 also decreased protein levels of $\mathrm{Bcl} 2$, contributing to its extensive apoptotic effect in cancer cells $[68,81]$. Moreover, overexpression of a double-negative FADD (Fas-associated death domain) protein to abrogate Fas/ DR5-mediated death receptor signaling and/or Bcl2 partially rescued the GANT61-induced cytotoxicity. This indicates that GANT61-induced cytotoxicity can be, at least partially, ascribed to effects on cell death.

A recent study by Lim et al. described a novel mechanism for GANT61-induced apoptosis in malignant mesothelioma cells. Induction of apoptosis by GANT61 was shown to be dependent on the production of mitochondrial reactive oxygen species (ROS), but independent of GLI1 or GLI2. Moreover, down-regulation of GLI1, GLI2 and PTCH gene levels by GANT61 was also shown to be mediated by ROS and could be counteracted by the addition of anti-oxidants, indicating that GANT61 at least partially acts through the induction of oxidative stress [82].

\section{DNA damage repair}

GANT61-induced cytotoxicity can also be ascribed to its inhibitory effect on DNA damage repair. Mazumdar et al. demonstrated that GANT61 was able to induce DNA double strand breaks (DSBs) marked by $\gamma \mathrm{H} 2 \mathrm{AX}$, an ATMdependent DNA damage response mechanism. Activation of ATM (p-ATM) and Chk2 (p-Chk2) was already shown $4 \mathrm{~h}$ after incubation. The latter resulted in the induction of DSBs and ultimately led to the induction of apoptosis after $24 \mathrm{~h}-48 \mathrm{~h}$. No effect of GANT61 was observed on the ATR/Chk1 axis [83]. In addition, Shi and colleagues performed a cDNA microarray of 18,401 genes to identify differentially expressed genes after GANT61 treatment in 
Table 2: Overview of GANT61 treatment in animal models.

\begin{tabular}{|c|c|c|c|c|c|c|}
\hline Tumor type & Animal model & Dose & Formulation & $\begin{array}{c}\text { Treatment } \\
\text { duration }\end{array}$ & Efficacy & Ref. \\
\hline Prostate & $\begin{array}{c}\text { 22Rv1 xenograft } \\
\text { (BALB/c nude (nu/nu) mice) }\end{array}$ & $50 \mathrm{mg} / \mathrm{kg}$ & $\begin{array}{l}\text { Every other day } \\
\text { (s.c. injection) }\end{array}$ & 16 days & $\begin{array}{l}\text { Tumor regression until no tumor } \\
\text { palpable }\end{array}$ & 58 \\
\hline Neuroblastoma & $\begin{array}{l}\text { SK-N-AS xenograft } \\
\text { (NMRI-nu/nu mice) }\end{array}$ & $50 \mathrm{mg} / \mathrm{kg}$ & $\begin{array}{c}\text { Daily } \\
\text { (gavage) }\end{array}$ & 12 days & $\begin{array}{l}\text { Tumor growth reduction }(63 \% \text { of } \\
\text { control) }\end{array}$ & 67 \\
\hline Pancreas & $\begin{array}{c}\text { Pancreatic CSC xenograft } \\
\text { (humanized NOD/SCID IL2 } \gamma \text { null mice) }\end{array}$ & $40 \mathrm{mg} / \mathrm{kg}$ & $\begin{array}{l}3 \text { times/week } \\
\text { (i.p. injection) }\end{array}$ & 6 weeks & CSC tumor growth inhibition & 68 \\
\hline Hepatocellular & $\begin{array}{l}\text { Huh7 xenograft } \\
\text { (SCID mice) }\end{array}$ & $50 \mathrm{mg} / \mathrm{kg}$ & $\begin{array}{l}\text { Every other day } \\
\text { (i.p. injection) }\end{array}$ & 4 weeks & Tumor growth reduction & 104 \\
\hline Lung & $\begin{array}{c}\text { NCI-H520, NCI-H2170 and NCI-H226 } \\
\text { xenograft } \\
\text { (immune deficient Ragl }{ }^{-1-} \text { mice) }\end{array}$ & $50 \mathrm{mg} / \mathrm{kg}$ & $\begin{array}{l}\text { Every other day } \\
\text { (i.p. injection) }\end{array}$ & 20 days & Tumor growth reduction & 79 \\
\hline Rhabdomysarcoma & $\begin{array}{l}\text { RD, RH30 xenograft } \\
\text { (athymic nu/nu mice) }\end{array}$ & $50 \mathrm{mg} / \mathrm{kg}$ & $\begin{array}{l}3 \text { times/week } \\
\text { (i.p. injection) }\end{array}$ & $\begin{array}{l}\text { Until tumor size } \\
\text { control mice } \\
>1 \mathrm{~cm}^{3} \\
(21-33 \text { days }) \\
\end{array}$ & $\begin{array}{c}\text { Tumor growth reduction ( } 53 \% \text { in RD } \\
\text { and } 47 \% \text { in RH30 cells compared to } \\
\text { control) }\end{array}$ & 77 \\
\hline $\begin{array}{l}\text { Embryonal } \\
\text { rhabdomyosarcoma }\end{array}$ & $\begin{array}{l}\text { CCA, Rh36 and A673 cells introduced in } \\
\text { Chick chorioallantantoic membrane } \\
\text { (CAM) assay }\end{array}$ & $10 \mu \mathrm{M} / 30 \mu \mathrm{M}$ & $\begin{array}{l}\text { Pre-mixture of cells } \\
\text { with GANT61 }\end{array}$ & 7 days & Decreased tumor volume & 106 \\
\hline
\end{tabular}

two colon cancer cell lines, HT29 and GC3/c1 cells. Gene expression of several molecules involved in the DNA damage repair was significantly decreased after GANT61 treatment [84].

\section{Migration}

Hh signaling is known to be implicated in epithelialmesenchymal transition (EMT) and therefore also in the initiation of metastasis. Fan et al. demonstrated upregulation of SHH, GLI1 and MMP9 and downregulation of E-cadherin in oral SCC tissue compared to normal tissue [43]. In addition, a negative correlation between GLI1 and E-cadherin was described in several studies $[43,85,86]$. Contrary, Joost et al. have shown that low GLI1 levels promote EMT in pancreatic ductal adenocarcinoma cells. Moreover, they also demonstrated that GLI1 directly regulates E-cadherin levels through binding with its promotor (CDH1) [87]. Chen et al. found that downregulation of GLI1 expression significantly suppressed adhesion, motility, migration, and invasion of hepatocellular carcinoma cells, which was correlated with reduced expression of MMP2 and MMP9, upregulation of E-cadherin, and concomitant down-regulation of Snail and Vimentin; all consistent with EMT inhibition [86].

Non-canonical Hh signaling has also been implicated in EMT regulation. Xu et al. describe an EMT molecular network mediated by Hh signaling in pancreatic cancer cells. Their data show that GLI1 signaling promotes EMT by inducing a complex signaling network including TGF $\beta$, PI3K, RAS and Wnt signaling [88]. Also, Ke et al. demonstrated that GLI1 promotes EMT, invasion and migration in ovarian cancer cells through crosstalk with PI3K signaling [89]. A recent study by Li et al. has shown that GLI1 regulates TGF $\beta$-induced EMT in non-small cell lung cancer cells. Inhibition of GLI1 with GANT61 attenuated induction of EMT by TGF $\beta$ [90]. Furthermore, another study indicated that invasion and EMT in pancreatic cancer cells is regulated by SDF1/CXCR4 signaling, which non-canonically activates $\mathrm{Hh}$ signaling in a SMO-dependent manner. Inhibition of $\mathrm{Hh}$ signaling through cyclopamine or GLI silencing blocked this SDF-1/CXCR4-mediated invasiveness [91].

Hypoxia also plays an important role in EMT and invasion. Work from Lei et al. has shown this is, at least partially, through activation of GLI1 by hypoxia. Knockdown of GLI1 did not have an effect on hypoxiainduced HIF $1 \alpha$ expression, but completely eliminated the hypoxia-induced vimentin and E-cadherin expression and tumor cell invasiveness $[92,93]$.

The effect of GANT61 on migration and invasion has been investigated in multiple studies. As expected, GANT61 has been shown to slow down cell migration and thus to decrease cell motility [78, 80, 94]. Furthermore, $\mathrm{Fu}$ and colleagues have also demonstrated that this is correlated with a decreased expression of the EMT markers Snail, Slug and Zeb1 in pancreatic cancer cells [68]. Inhibition of GLI signaling by means of GANT61 could hence be a promising target to decrease tumor cell motility and invasiveness.

\section{Cancer stem cells}

Several studies have indicated that Hh signaling plays a key role in the regulation of cancer stem cells (CSCs), by controlling the transcription of a number of genes implicated in cell fate determination and stemness features, i.e. self-renewal and pluripotency [68, 95-97]. Work of Santini et al. has shown that melanomas contain a subpopulation of cells expressing high ALDH activity $\left(\mathrm{ALDH}^{\text {high }}\right)$, which is correlated with a higher ability to self-renew and tumorigenicity. GANT61 significantly 
reduced the number and self-renewal capacity of these melanoma CSCs and also decreased tumor initiation in vivo [96]. Similarly, a study by Heiden et al. showed that inhibition of GLI1 significantly reduced the number of $\mathrm{ALDH}^{\text {high }}$ thyroid CSCs. Overexpression of GLI1 on the other hand increased the number and the selfrenewal of these cells [97]. Furthermore, silencing of SOX2 in melanoma CSCs also decreased self-renewal in vitro and limited in vivo tumor initiation and growth of melanoma stem cells. Hh signaling directly regulates SOX2 transcription through direct binding of the GLI transcription factors in the promotor region of SOX2, indicating that the effect of GANT61 is at least partially mediated by SOX2 [98]. This is in line with another study by $\mathrm{Fu}$ et al. in which the authors have demonstrated that GANT61 significantly decreases protein levels of several markers of self-renewal such as SOX2, NANOG, OCT4 and cMYC. Moreover, GANT61 inhibited pancreatic CSC tumor growth in NOD/SCID IL2R $\gamma$ null mice [68].

It is well known that CSCs are more resistant to chemo- and radiotherapy [99, 100]. The use of $\mathrm{Hh}$ inhibition in combination with chemotherapeutics could be a promising strategy. Indeed, GANT61 has been shown to potentiate the effect of chemotherapeutics in neuroblastoma cells [67] and biliary tract cancer cells [35] in an additive and/or synergistic manner. In a model of alternating therapies proposed by Blagoskonny [101], Hh-dependent cancer cells could first be targeted with $\mathrm{Hh}$ inhibitors. Over time, acquired resistance to these drugs may occur, as has already been observed with the use of vismodegib in BCC patients. Since the relapsed tumor will still be dependent on universally-vital targets, it can then be targeted with chemotherapeutics. As chemotherapy preferentially kills proliferating cells, it may spare CSC that are driven by embryonic/stem pathways such as the Hh signaling. Moreover, resistance against chemotherapy has often been associated with an upregulation of developmental pathways, such as Hh, Wnt and Notch signaling [102]. Therefore, once chemoresistance has occurred, the relapsed tumor might be sensitive to Hh inhibitors again. Next to that, GANT61 could also be an attractive target to sensitize radioresistant CSCs to radiation treatment, as it has been shown that knockdown of SHH or GLI significantly reduced clonogenic survival, while expression of GLI1 was correlated with the number of surviving colonies after ionizing radiation [97].

\section{Autophagy}

Several studies have shown that GANT61 induces autophagy, contributing to decreased cell viability and increased apoptosis. Inhibition of autophagy decreased the GANT61-induced apoptosis both in vitro and in vivo in hepatocellular and pancreatic cancer cells, highlighting the role of autophagy in GANT61-induced cytotoxicity $[103,104]$.

\section{Immune response}

Little is known about the role of Hh signaling in the immune response. A study by Yoshimoto et al. illustrated that GANT61 increased the production of the inflammatory cytokines IL8 and MCP1, thereby increasing monocyte recruitment in CT26 colon cancer cells. Activation of Hh signaling appeared thus to be associated with an anti-inflammatory effect in colon cancer cells [105].

\section{Therapeutic potential of GANT61 in animal models}

Besides the promising results of GANT61 in in vitro studies, also several animal studies have shown significant decreases in tumor growth upon GANT61 treatment (Table 2) [58, 67, 68, 77, 79, 104, 106]. Lauth et al. even reported complete tumor regression in a $22 \mathrm{Rv} 1$ prostate cancer xenograft mouse model. Treatment with GANT61 significantly decreased BrdU incorporation and increased apoptosis in these tumor compared to controls [58].

These promising results highlight the potential of targeting Hh signaling at the level of the GLI transcription factors. The observed effect on tumor growth does not seem to be dependent on the administration route, since several types of drug delivery (intra-peritoneal injection, subcutaneous injection or orally) have been used, all resulting in a significant growth delay. None of these studies reported any toxicity due to GANT61 treatment; however, there is little/no knowledge on the pharmacokinetics (e.g. solubility, metabolism, etc.) of this agent.

\section{Combined modality treatment}

As already indicated for a few times, the Hh signaling interacts with multiple signaling pathways at several levels of the signaling cascade. Most important pathways are the RAS/RAF/MEK/ERK, PI3K/AKT/ mTOR, epidermal growth factor receptor (EGFR) and Notch signaling, which all interact at the level of the GLI transcription factors, except for Notch which interferes with the ligand SHH. Combined treatment modalities could be useful to overcome or delay resistance frequently observed after long-term treatment with a single agent such as vismodegib or tyrosine kinase inhibitors. Especially the combination of $\mathrm{Hh}$ and PI3K signaling inhibition could be beneficial, since one potential mechanism of resistance against SMO inhibition has been ascribed to upregulation of PI3K signaling. Combination of a PI3K inhibitor (BKM120 or BEZ235) and SMO inhibitor (LDE225) delayed the development of resistance in a MB mouse model, although no effect was observed on tumor growth [27]. This combination is currently under clinical 
investigation in patients with advanced or metastatic BCC (NCT02303041) and patients with advanced solid tumors (NCT01576666).

Another promising combination strategy could be the combination of an mTOR inhibitor and GANT61. Two independent studies have already shown that this combination is significantly more effective than either single treatment. In the first study, Pan et al. have demonstrated a synergistic effect of rapamycin and GANT61 in myeloid leukemia cells [107]. The second study by Srivastava et al. indicated that GANT61mediated cytotoxicity was significantly more pronounced in combination with mTOR inhibitors emsirolimus and rapamycin, but also in combination with the chemotherapeutic agent vincristine in rhabdomyosarcoma cells [77].

As mentioned earlier, combination of Hh inhibition with radiotherapy might also be a promising strategy to increase the sensitiveness of certain radioresistant types of cancer. A very recent study by Zhou et al investigated the role of GLI1 in radioresistance and found that GANT61 could increase radiosensitivity of renal cell carcinoma cells through hampering of DNA damage repair. Moreover, simultaneously targeting of GLI1 and HIF $2 \alpha$ turned out to be even more effective [108].

\section{CONCLUSIONS AND FUTURE PERSPECTIVES}

In recent years, the $\mathrm{Hh}$ signaling pathway has proven to be an essential key player in tumor initiation and/or progression to more advanced tumor stages. Numerous SMO inhibitors are currently on the market of which several are under clinical investigation. Initially, SMO inhibitors seemed to be very efficient in ligandindependent tumor types, such as BCC and MB, but unfortunately resistance against these agents has already been observed. Moreover, the effect of SMO inhibitors in other (ligand-dependent) types of cancer seems to be very limited, highlighting the importance of identifying new target sites. The most promising targets within the Hh signaling pathway are by far the GLI transcription factors for several reasons. First, these molecules are most downstream of the signaling pathway, meaning that small molecules targeting the GLI transcription factors will still be effective in tumors harboring mutations in SMO or even more downstream of SMO (e.g. SUFU). Additionally, non-canonical activation of the GLI transcription factors occurs by several important oncogenic pathways, which would render these tumors insensitive to inhibitors more upstream of the Hh signaling cascade. With this review, we attempted to highlight the importance of targeting $\mathrm{Hh}$ signaling more downstream of SMO, more specifically, at the level of the GLI transcription factors. In the second part of this review, we summarized currently published data on the GLI1/2 inhibitor GANT61, underlining its efficacy and the different mechanisms by which this agent interacts with cancer cells. In conclusion, GANT61 appears to be highly effective against human cancer cells and in xenograft mouse models, targeting almost all of the classical hallmarks of cancer and could hence represent a promising treatment option for human cancer. However, the impact of GLI inhibition on other important cancer mechanisms such as angiogenesis has not yet been investigated and should be examined, since this would have major implications for the future use of GANT61. Additionally, at the moment there is little/no knowledge on the pharmacokinetics (e.g. solubility, metabolism, etc.) of this agent and its toxicity.

\section{ACKNOWLEDGMENTS}

A.G. and S.I. are sponsored by a grant from the National Cancer Plan Action 29 Belgium (KPC_29_023). K.H. is a clinical research fellow of the Research Foundation Flanders.

\section{CONFLICTS OF INTEREST}

The authors declare no conflict of interest.

\section{REFERENCES}

1. Teglund S, Toftgard R. Hedgehog beyond medulloblastoma and basal cell carcinoma. Biochim Biophys Acta. 2010; 1805: 181-208.

2. Yang L, Xie G, Fan Q, Xie J. Activation of the hedgehogsignaling pathway in human cancer and the clinical implications. Oncogene. 2010; 29: 469-481.

3. Kogerman P, Grimm T, Kogerman L, Krause D, Unden AB, Sandstedt B, Toftgard R, Zaphiropoulos PG. Mammalian suppressor-of-fused modulates nuclear-cytoplasmic shuttling of Gli-1. Nat Cell Biol. 1999; 1: 312-319.

4. Humke EW, Dorn KV, Milenkovic L, Scott MP, Rohatgi $\mathrm{R}$. The output of Hedgehog signaling is controlled by the dynamic association between Suppressor of Fused and the Gli proteins. Genes Dev. 2010; 24: 670-682.

5. Scales SJ, de Sauvage FJ. Mechanisms of Hedgehog pathway activation in cancer and implications for therapy. Trends Pharmacol Sci. 2009; 30: 303-312.

6. Stecca B, Ruiz IA. Context-dependent regulation of the GLI code in cancer by HEDGEHOG and non-HEDGEHOG signals. J Mol Cell Biol. 2010; 2: 84-95.

7. Jenkins D. Hedgehog signalling: emerging evidence for non-canonical pathways. Cell Signal. 2009; 21: 1023-1034.

8. Brennan D, Chen X, Cheng L, Mahoney M, Riobo NA. Noncanonical Hedgehog signaling. Vitam Horm. 2012; 88:55-72.

9. Onishi H, Katano M. Hedgehog signaling pathway as a therapeutic target in various types of cancer. Cancer Sci. 
2011; 102: 1756-1760.

10. Aberger F, Ruiz IA. Context-dependent signal integration by the GLI code: the oncogenic load, pathways, modifiers and implications for cancer therapy. Semin Cell Dev Biol. 2014; 33:93-104.

11. Lauth M, Toftgard R. Non-canonical activation of GLI transcription factors: implications for targeted anti-cancer therapy. Cell Cycle. 2007; 6: 2458-2463.

12. Pasca di MM, Hebrok M. Hedgehog signalling in cancer formation and maintenance. Nat Rev Cancer. 2003; 3(12): 903-911.

13. Gonnissen A, Isebaert S, Haustermans K. Hedgehog signaling in prostate cancer and its therapeutic implication. Int J Mol Sci. 2013; 14: 13979-14007.

14. Szkandera J, Kiesslich T, Haybaeck J, Gerger A, Pichler M. Hedgehog signaling pathway in ovarian cancer. Int J Mol Sci. 2013; 14: 1179-1196.

15. Rubin LL, de Sauvage FJ. Targeting the Hedgehog pathway in cancer. Nat Rev Drug Discov. 2006; 5: 1026-1033.

16. Chen JK, Taipale J, Cooper MK, Beachy PA. Inhibition of Hedgehog signaling by direct binding of cyclopamine to Smoothened. Genes Dev. 2002; 16: 2743-2748.

17. Ng JM, Curran T. The Hedgehog's tale: developing strategies for targeting cancer. Nat Rev Cancer. 2011; 11: 493-501.

18. Sekulic A, Migden MR, Oro AE, Dirix L, Lewis KD, Hainsworth JD, Solomon JA, Yoo S, Arron ST, Friedlander PA, Marmur E, Rudin CM, Chang AL, Low JA, Mackey HM, Yauch RL, Graham RA, Reddy JC, Hauschild A. Efficacy and safety of vismodegib in advanced basal-cell carcinoma. N Engl J Med. 2012; 366: 2171-2179.

19. Rodon J, Tawbi HA, Thomas AL, Stoller RG, Turtschi CP, Baselga J, Sarantopoulos J, Mahalingam D, Shou Y, Moles MA, Yang L, Granvil C, Hurh E, Rose KL, Amakye DD, Dummer R, Mita AC. A phase I, multicenter, openlabel, first-in-human, dose-escalation study of the oral smoothened inhibitor Sonidegib (LDE225) in patients with advanced solid tumors. Clin Cancer Res. 2014; 20: 19001909.

20. Jimeno A, Weiss GJ, Miller WH, Jr., Gettinger S, Eigl BJ, Chang AL, Dunbar J, Devens S, Faia K, Skliris G, Kutok J, Lewis KD, Tibes R, Sharfman WH, Ross RW, Rudin CM. Phase I study of the Hedgehog pathway inhibitor IPI-926 in adult patients with solid tumors. Clin Cancer Res. 2013; 19: 2766-2774.

21. LoRusso PM, Rudin CM, Reddy JC, Tibes R, Weiss GJ, Borad MJ, Hann CL, Brahmer JR, Chang I, Darbonne WC, Graham RA, Zerivitz KL, Low JA, Von Hoff DD. Phase I trial of hedgehog pathway inhibitor vismodegib (GDC0449) in patients with refractory, locally advanced or metastatic solid tumors. Clin Cancer Res. 2011; 17: 25022511.

22. Atwood SX, Chang AL, Oro AE. Hedgehog pathway inhibition and the race against tumor evolution. J Cell Biol.
2012; 199: 193-197.

23. Rudin CM, Hann CL, Laterra J, Yauch RL, Callahan CA, Fu L, Holcomb T, Stinson J, Gould SE, Coleman B, LoRusso PM, Von Hoff DD, de Sauvage FJ, Low JA. Treatment of medulloblastoma with hedgehog pathway inhibitor GDC-0449. N Engl J Med. 2009; 361: 1173-1178.

24. Chang AL, Oro AE. Initial assessment of tumor regrowth after vismodegib in advanced Basal cell carcinoma. Arch Dermatol. 2012; 148: 1324-1325.

25. Yauch RL, Dijkgraaf GJ, Alicke B, Januario T, Ahn CP, Holcomb T, Pujara K, Stinson J, Callahan CA, Tang T, Bazan JF, Kan Z, Seshagiri S, Hann CL, Gould SE, Low JA, Rudin CM, de Sauvage FJ. Smoothened mutation confers resistance to a Hedgehog pathway inhibitor in medulloblastoma. Science. 2009; 326: 572-574.

26. Dijkgraaf GJ, Alicke B, Weinmann L, Januario T, West K, Modrusan Z, Burdick D, Goldsmith R, Robarge K, Sutherlin D, Scales SJ, Gould SE, Yauch RL, de Sauvage FJ. Small molecule inhibition of GDC-0449 refractory smoothened mutants and downstream mechanisms of drug resistance. Cancer Res. 2011; 71: 435-444.

27. Buonamici S, Williams J, Morrissey M, Wang A, Guo R, Vattay A, Hsiao K, Yuan J, Green J, Ospina B, Yu Q, Ostrom L, Fordjour P, Anderson DL, Monahan JE, Kelleher JF, Peukert S, Pan S, Wu X, Maira SM, Garcia-Echeverria C, Briggs KJ, Watkins DN, Yao YM, Lengauer C, Warmuth M, Sellers WR, Dorsch M. Interfering with resistance to smoothened antagonists by inhibition of the PI3K pathway in medulloblastoma. Sci Transl Med. 2010; 2: 51ra70-

28. Metcalfe C, de Sauvage FJ. Hedgehog fights back: mechanisms of acquired resistance against Smoothened antagonists. Cancer Res. 2011; 71: 5057-5061.

29. Kinzler KW, Bigner SH, Bigner DD, Trent JM, Law ML, O'Brien SJ, Wong AJ, Vogelstein B. Identification of an amplified, highly expressed gene in a human glioma. Science. 1987; 236: 70-73.

30. Thompson MC, Fuller C, Hogg TL, Dalton J, Finkelstein D, Lau CC, Chintagumpala M, Adesina A, Ashley DM, Kellie SJ, Taylor MD, Curran T, Gajjar A, Gilbertson RJ. Genomics identifies medulloblastoma subgroups that are enriched for specific genetic alterations. J Clin Oncol. 2006; 24: 1924-1931.

31. Zibat A, Missiaglia E, Rosenberger A, Pritchard-Jones K, Shipley J, Hahn H, Fulda S. Activation of the hedgehog pathway confers a poor prognosis in embryonal and fusion gene-negative alveolar rhabdomyosarcoma. Oncogene. 2010; 29: 6323-6330.

32. Tostar U, Malm CJ, Meis-Kindblom JM, Kindblom LG, Toftgard R, Unden AB. Deregulation of the hedgehog signalling pathway: a possible role for the PTCH and SUFU genes in human rhabdomyoma and rhabdomyosarcoma development. J Pathol. 2006; 208: 17-25.

33. Karhadkar SS, Bova GS, Abdallah N, Dhara S, Gardner D, Maitra A, Isaacs JT, Berman DM, Beachy PA. Hedgehog 
signalling in prostate regeneration, neoplasia and metastasis. Nature. 2004; 431: 707-712.

34. Kim TJ, Lee JY, Hwang TK, Kang CS, Choi YJ. Hedgehog signaling protein expression and its association with prognostic parameters in prostate cancer: a retrospective study from the view point of new 2010 anatomic stage/ prognostic groups. J Surg Oncol. 2011; 104: 472-479.

35. Kiesslich T, Mayr C, Wachter J, Bach D, Fuereder J, Wagner A, Alinger B, Pichler M, Di FP, Ocker M, Berr F, Neureiter D. Activated hedgehog pathway is a potential target for pharmacological intervention in biliary tract cancer. Mol Cell Biochem. 2014; 396: 257-68.

36. Kubo M, Nakamura M, Tasaki A, Yamanaka N, Nakashima H, Nomura M, Kuroki S, Katano M. Hedgehog signaling pathway is a new therapeutic target for patients with breast cancer. Cancer Res. 2004; 64: 6071-6074.

37. ten HA, Bektas N, von SS, Losen I, Arweiler EC, Hartmann A, Knuchel R, Dahl E. Expression of the glioma-associated oncogene homolog (GLI) 1 in human breast cancer is associated with unfavourable overall survival. BMC Cancer. 2009; 9: 298.

38. Souzaki M, Kubo M, Kai M, Kameda C, Tanaka H, Taguchi T, Tanaka M, Onishi H, Katano M. Hedgehog signaling pathway mediates the progression of non-invasive breast cancer to invasive breast cancer. Cancer Sci. 2011; 102: 373-381.

39. Hong Z, Bi A, Chen D, Gao L, Yin Z, Luo L. Activation of hedgehog signaling pathway in human non-small cell lung cancers. Pathol Oncol Res. 2014; 20(4): 917-922.

40. Xu M, Li X, Liu T, Leng A, Zhang G. Prognostic value of hedgehog signaling pathway in patients with colon cancer. Med Oncol. 2012; 29: 1010-1016.

41. Varnat F, Duquet A, Malerba M, Zbinden M, Mas C, Gervaz P, Altaba A. Human colon cancer epithelial cells harbour active HEDGEHOG-GLI signalling that is essential for tumour growth, recurrence, metastasis and stem cell survival and expansion. EMBO Mol Med. 2009; 1: 338351.

42. He HC, Chen JH, Chen XB, Qin GQ, Cai C, Liang YX, Han ZD, Dai QS, Chen YR, Zeng GH, Zhu JG, Jiang FN, Zhong WD. Expression of hedgehog pathway components is associated with bladder cancer progression and clinical outcome. Pathol Oncol Res. 2012; 18: 349-355.

43. Fan HX, Wang S, Zhao H, Liu N, Chen D, Sun M, Zheng JH. Sonic hedgehog signaling may promote invasion and metastasis of oral squamous cell carcinoma by activating MMP-9 and E-cadherin expression. Med Oncol. 2014; 31: 41.

44. Chung CH, Dignam JJ, Hammond ME, Klimowicz AC, Petrillo SK, Magliocco A, Jordan R, Trotti A, Spencer S, Cooper JS, Le QT, Ang KK. Glioma-associated oncogene family zinc finger 1 expression and metastasis in patients with head and neck squamous cell carcinoma treated with radiation therapy (RTOG 9003). J Clin Oncol. 2011; 29:
1326-1334.

45. Kar S, Deb M, Sengupta D, Shilpi A, Bhutia SK, Patra SK. Intricacies of hedgehog signaling pathways: a perspective in tumorigenesis. Exp Cell Res. 2012; 318: 1959-1972.

46. Datta S, Datta MW. Sonic Hedgehog signaling in advanced prostate cancer. Cell Mol Life Sci. 2006; 63: 435-448.

47. Mas C, Altaba A. Small molecule modulation of HH-GLI signaling: current leads, trials and tribulations. Biochem Pharmacol. 2010; 80: 712-723.

48. Kim J, Tang JY, Gong R, Kim J, Lee JJ, Clemons KV, Chong CR, Chang KS, Fereshteh M, Gardner D, Reya T, Liu JO, Epstein EH, Stevens DA, Beachy PA. Itraconazole, a commonly used antifungal that inhibits Hedgehog pathway activity and cancer growth. Cancer Cell. 2010; 17: 388-399.

49. Kim J, Aftab BT, Tang JY, Kim D, Lee AH, Rezaee M, Kim J, Chen B, King EM, Borodovsky A, Riggins GJ, Epstein EH, Jr., Beachy PA, Rudin CM. Itraconazole and arsenic trioxide inhibit Hedgehog pathway activation and tumor growth associated with acquired resistance to smoothened antagonists. Cancer Cell. 2013; 23: 23-34.

50. Hosoya T, Arai MA, Koyano T, Kowithayakorn T, Ishibashi M. Naturally occurring small-molecule inhibitors of hedgehog/GLI-mediated transcription. Chembiochem. 2008; 9: 1082-1092.

51. Huntzicker EG, Estay IS, Zhen H, Lokteva LA, Jackson PK, Oro AE. Dual degradation signals control Gli protein stability and tumor formation. Genes Dev. 2006; 20: 276281.

52. Hyman JM, Firestone AJ, Heine VM, Zhao Y, Ocasio CA, Han K, Sun M, Rack PG, Sinha S, Wu JJ, Solow-Cordero DE, Jiang J, Rowitch DH, Chen JK. Small-molecule inhibitors reveal multiple strategies for Hedgehog pathway blockade. Proc Natl Acad Sci U S A. 2009; 106: 1413214137.

53. Wolff F, Loipetzberger A, Gruber W, Esterbauer H, Aberger F, Frischauf AM. Imiquimod directly inhibits Hedgehog signalling by stimulating adenosine receptor/ protein kinase A-mediated GLI phosphorylation. Oncogene. 2013; 32: 5574-5581.

54. Gruber W, Frischauf AM, Aberger F. An old friend with new skills: Imiquimod as novel inhibitor of Hedgehog signaling in basal cell carcinoma. Oncoscience. 2014; 1: 567-573.

55. Kim J, Lee JJ, Kim J, Gardner D, Beachy PA. Arsenic antagonizes the Hedgehog pathway by preventing ciliary accumulation and reducing stability of the Gli2 transcriptional effector. Proc Natl Acad Sci U S A. 2010; 107: 13432-13437.

56. Pavletich NP, Pabo CO. Crystal structure of a five-finger GLI-DNA complex: new perspectives on zinc fingers. Science. 1993; 261: 1701-1707.

57. Kinzler KW, Vogelstein B. The GLI gene encodes a nuclear protein which binds specific sequences in the human 
genome. Mol Cell Biol. 1990; 10: 634-642.

58. Lauth M, Bergstrom A, Shimokawa T, Toftgard R. Inhibition of GLI-mediated transcription and tumor cell growth by small-molecule antagonists. Proc Natl Acad Sci U S A. 2007; 104: 8455-8460.

59. Agyeman A, Jha BK, Mazumdar T, Houghton JA. Mode and specificity of binding of the small molecule GANT61 to GLI determines inhibition of GLI-DNA binding. Oncotarget. 2014; 5: 4492-4503.

60. Infante $\mathrm{P}$, Mori M, Alfonsi R, Ghirga F, Aiello F, Toscano S, Ingallina C, Siler M, Cucchi D, Po A, Miele E, D’Amico D, Canettieri G, De SE, Ferretti E, Screpanti I, Uccello BG, Botta M, Botta B, Gulino A, Di ML. Gli1/DNA interaction is a druggable target for Hedgehog-dependent tumors. EMBO J. 2015; 34: 200-17.

61. Tang Y, Gholamin S, Schubert S, Willardson MI, Lee A, Bandopadhayay P, Bergthold G, Masoud S, Nguyen B, Vue N, Balansay B, Yu F, Oh S, Woo P, Chen S, Ponnuswami A, Monje M, Atwood SX, Whitson RJ, Mitra S, Cheshier SH, Qi J, Beroukhim R, Tang JY, Wechsler-Reya R, Oro AE, Link BA, Bradner JE, Cho YJ. Epigenetic targeting of Hedgehog pathway transcriptional output through BET bromodomain inhibition. Nat Med. 2014; 20: 732-740.

62. Long J, Li B, Rodriguez-Blanco J, Pastori C, Volmar CH, Wahlestedt C, Capobianco A, Bai F, Pei XH, Ayad NG, Robbins DJ. The BET Bromodomain Inhibitor I-BET151 Acts Downstream of Smoothened Protein to Abrogate the Growth of Hedgehog Protein-driven Cancers. J Biol Chem. 2014; 289: 35494-35502.

63. Shi J, Vakoc CR. The mechanisms behind the therapeutic activity of BET bromodomain inhibition. Mol Cell. 2014; 54: 728-736.

64. Wang Y, Ding Q, Yen CJ, Xia W, Izzo JG, Lang JY, Li CW, Hsu JL, Miller SA, Wang X, Lee DF, Hsu JM, Huo L, Labaff AM, Liu D, Huang TH, Lai CC, Tsai FJ, Chang WC, Chen CH, Wu TT, Buttar NS, Wang KK, Wu Y, Wang $\mathrm{H}$, Ajani J, Hung MC. The crosstalk of mTOR/S6K1 and Hedgehog pathways. Cancer Cell. 2012; 21: 374-387.

65. You M, Varona-Santos J, Singh S, Robbins DJ, Savaraj N, Nguyen DM. Targeting of the Hedgehog signal transduction pathway suppresses survival of malignant pleural mesothelioma cells in vitro. J Thorac Cardiovasc Surg. 2014; 147: 508-516.

66. Desch P, Asslaber D, Kern D, Schnidar H, Mangelberger D, Alinger B, Stoecher M, Hofbauer SW, Neureiter D, Tinhofer I, Aberger F, Hartmann TN, Greil R. Inhibition of GLI, but not Smoothened, induces apoptosis in chronic lymphocytic leukemia cells. Oncogene. 2010; 29: 48854895.

67. Wickstrom M, Dyberg C, Shimokawa T, Milosevic J, Baryawno N, Fuskevag OM, Larsson R, Kogner P, Zaphiropoulos PG, Johnsen JI. Targeting the hedgehog signal transduction pathway at the level of GLI inhibits neuroblastoma cell growth in vitro and in vivo. Int J Cancer. 2013; 132: 1516-1524
68. Fu J, Rodova M, Roy SK, Sharma J, Singh KP, Srivastava RK, Shankar S. GANT-61 inhibits pancreatic cancer stem cell growth in vitro and in NOD/SCID/IL2R gamma null mice xenograft. Cancer Lett. 2013; 330: 22-32.

69. Neidle S, Parkinson GN. The structure of telomeric DNA. Curr Opin Struct Biol. 2003; 13: 275-283.

70. Blasco MA, Hahn WC. Evolving views of telomerase and cancer. Trends Cell Biol. 2003; 13: 289-294.

71. Poole JC, Andrews LG, Tollefsbol TO. Activity, function, and gene regulation of the catalytic subunit of telomerase (hTERT). Gene. 2001; 269: 1-12.

72. Kirkpatrick KL, Ogunkolade W, Elkak AE, Bustin S, Jenkins P, Ghilchick M, Newbold RF, Mokbel K. hTERT expression in human breast cancer and non-cancerous breast tissue: correlation with tumour stage and c-Myc expression. Breast Cancer Res Treat. 2003; 77: 277-284.

73. Zhang Y, Toh L, Lau P, Wang X. Human telomerase reverse transcriptase (hTERT) is a novel target of the Wnt/ beta-catenin pathway in human cancer. J Biol Chem. 2012; 287: 32494-32511.

74. $\mathrm{Xu} \mathrm{D,} \mathrm{Wang} \mathrm{Q,} \mathrm{Gruber} \mathrm{A,} \mathrm{Bjorkholm} \mathrm{M,} \mathrm{Chen} \mathrm{Z,}$ Zaid A, Selivanova G, Peterson C, Wiman KG, Pisa $P$. Downregulation of telomerase reverse transcriptase mRNA expression by wild type p53 in human tumor cells. Oncogene. 2000; 19: 5123-5133.

75. Yatabe N, Kyo S, Maida Y, Nishi H, Nakamura M, Kanaya T, Tanaka M, Isaka K, Ogawa S, Inoue M. HIF-1-mediated activation of telomerase in cervical cancer cells. Oncogene. 2004; 23: 3708-3715.

76. Mazumdar T, Sandhu R, Qadan M, Devecchio J, Magloire V, Agyeman A, Li B, Houghton JA. Hedgehog signaling regulates telomerase reverse transcriptase in human cancer cells. PLoS One. 2013; 8:e75253.

77. Srivastava RK, Kaylani SZ, Edrees N, Li C, Talwelkar SS, Xu J, Palle K, Pressey JG, Athar M. GLI inhibitor GANT61 diminishes embryonal and alveolar rhabdomyosarcoma growth by inhibiting Shh/AKT-mTOR axis. Oncotarget. 2014; 5: 12151-12165.

78. Yan M, Wang L, Zuo H, Zhang Z, Chen W, Mao L, Zhang P. HH/GLI signalling as a new therapeutic target for patients with oral squamous cell carcinoma. Oral Oncol. 2011; 47: 504-509.

79. Huang L, Walter V, Hayes DN, Onaitis M. Hedgehog-GLI signaling inhibition suppresses tumor growth in squamous lung cancer. Clin Cancer Res. 2014; 20: 1566-1575.

80. Yan R, Peng X, Yuan X, Huang D, Chen J, Lu Q, Lv N, Luo S. Suppression of growth and migration by blocking the Hedgehog signaling pathway in gastric cancer cells. Cell Oncol (Dordr ). 2013; 36: 421-435.

81. Mazumdar T, Devecchio J, Shi T, Jones J, Agyeman A, Houghton JA. Hedgehog signaling drives cellular survival in human colon carcinoma cells. Cancer Res. 2011; 71: 1092-1102.

82. Lim CB, Prele CM, Baltic S, Arthur PG, Creaney J, 
Watkins DN, Thompson PJ, Mutsaers SE. Mitochondriaderived reactive oxygen species drive GANT61-induced mesothelioma cell apoptosis. Oncotarget. 2015; 6: 15191530 .

83. Mazumdar T, Devecchio J, Agyeman A, Shi T, Houghton JA. Blocking Hedgehog survival signaling at the level of the GLI genes induces DNA damage and extensive cell death in human colon carcinoma cells. Cancer Res. 2011; 71: 5904-5914.

84. Shi T, Mazumdar T, Devecchio J, Duan ZH, Agyeman A, Aziz M, Houghton JA. cDNA microarray gene expression profiling of hedgehog signaling pathway inhibition in human colon cancer cells. PLoS One. 2010; 5: e13054.

85. Yue D, Li H, Che J, Zhang Y, Tseng HH, Jin JQ, Luh TM, Giroux-Leprieur E, Mo M, Zheng Q, Shi H, Zhang H, Hao X, Wang C, Jablons DM, He B. Hedgehog/Gli promotes epithelial-mesenchymal transition in lung squamous cell carcinomas. J Exp Clin Cancer Res. 2014; 33: 34.

86. Chen JS, Li HS, Huang JQ, Zhang LJ, Chen XL, Wang Q, Lei J, Feng JT, Liu Q, Huang XH. Down-regulation of Gli-1 inhibits hepatocellular carcinoma cell migration and invasion. Mol Cell Biochem. 2014; 393: 283-291.

87. Joost S, Almada LL, Rohnalter V, Holz PS, Vrabel AM, Fernandez-Barrena MG, McWilliams RR, Krause M, Fernandez-Zapico ME, Lauth M. GLI1 inhibition promotes epithelial-to-mesenchymal transition in pancreatic cancer cells. Cancer Res. 2012; 72: 88-99.

88. Xu X, Zhou Y, Xie C, Wei SM, Gan H, He S, Wang F, Xu L, Lu J, Dai W, He L, Chen P, Wang X, Guo C. Genome-wide screening reveals an EMT molecular network mediated by Sonic hedgehog-Gli1 signaling in pancreatic cancer cells. PLoS One. 2012; 7: e43119.

89. Ke Z, Caiping S, Qing Z, Xiaojing W. Sonic hedgehogGli1 signals promote epithelial-mesenchymal transition in ovarian cancer by mediating PI3K/AKT pathway. Med Oncol. 2015; 32: 368.

90. Li H, Da LJ, Fan WD, Long XH, Zhang XQ. Transcription factor glioma-associated oncogene homolog 1 is required for transforming growth factor-beta1-induced epithelialmesenchymal transition of non-small cell lung cancer cells. Mol Med Rep. 2015; 11: 3259-3268.

91. Li X, Ma Q, Xu Q, Liu H, Lei J, Duan W, Bhat K, Wang F, Wu E, Wang Z. SDF-1/CXCR4 signaling induces pancreatic cancer cell invasion and epithelial-mesenchymal transition in vitro through non-canonical activation of Hedgehog pathway. Cancer Lett. 2012; 322: 169-176.

92. Lei J, Fan L, Wei G, Chen X, Duan W, Xu Q, Sheng W, Wang K, Li X. Gli-1 is crucial for hypoxia-induced epithelial-mesenchymal transition and invasion of breast cancer. Tumour Biol. 2015; 36: 3119-26.

93. Lei J, Ma J, Ma Q, Li X, Liu H, Xu Q, Duan W, Sun Q, $\mathrm{Xu} \mathrm{J}, \mathrm{Wu} \mathrm{Z}, \mathrm{Wu}$ E. Hedgehog signaling regulates hypoxia induced epithelial to mesenchymal transition and invasion in pancreatic cancer cells via a ligand-independent manner.
Mol Cancer. 2013; 12: 66.

94. Samarzija I, Beard P. Hedgehog pathway regulators influence cervical cancer cell proliferation, survival and migration. Biochem Biophys Res Commun. 2012; 425: 6469.

95. Coni S, Infante P, Gulino A. Control of stem cells and cancer stem cells by Hedgehog signaling: Pharmacologic clues from pathway dissection. Biochem Pharmacol. 2013; 85: 623-628.

96. Santini R, Vinci MC, Pandolfi S, Penachioni JY, Montagnani V, Olivito B, Gattai R, Pimpinelli N, Gerlini G, Borgognoni L, Stecca B. Hedgehog-GLI signaling drives self-renewal and tumorigenicity of human melanomainitiating cells. Stem Cells. 2012; 30: 1808-1818.

97. Heiden KB, Williamson AJ, Doscas ME, Ye J, Wang Y, Liu D, Xing M, Prinz RA, Xu X. The sonic hedgehog signaling pathway maintains the cancer stem cell self-renewal of anaplastic thyroid cancer by inducing Snail expression. J Clin Endocrinol Metab. 2014; 99: e2178-87.

98. Santini R, Pietrobono S, Pandolfi S, Montagnani V, D’Amico M, Penachioni JY, Vinci MC, Borgognoni L, Stecca B. SOX2 regulates self-renewal and tumorigenicity of human melanoma-initiating cells. Oncogene. 2014; 33: 4697-4708.

99. Croker AK, Allan AL. Cancer stem cells: implications for the progression and treatment of metastatic disease. J Cell Mol Med. 2008; 12: 374-390.

100. Gilbertson RJ, Graham TA. Cancer: Resolving the stem-cell debate. Nature. 2012; 488: 462-463.

101. Blagosklonny MV. Teratogens as anti-cancer drugs. Cell Cycle. 2005; 4: 1518-1521.

102. Janikova M, Skarda J. Differentiation pathways in carcinogenesis and in chemo- and radioresistance. Neoplasma. 2012; 59: 6-17.

103. Xu Y, An Y, Wang X, Zha W, Li X. Inhibition of the Hedgehog pathway induces autophagy in pancreatic ductal adenocarcinoma cells. Oncol Rep. 2014; 31: 707-712.

104. Wang Y, Han C, Lu L, Magliato S, Wu T. Hedgehog signaling pathway regulates autophagy in human hepatocellular carcinoma cells. Hepatology. 2013; 58: 995 1010.

105. Yoshimoto AN, Bernardazzi C, Carneiro AJ, Elia CC, Martinusso CA, Ventura GM, Castelo-Branco MT, de Souza HS. Hedgehog pathway signaling regulates human colon carcinoma HT-29 epithelial cell line apoptosis and cytokine secretion. PLoS One. 2012; 7: e45332.

106. Tostar U, Toftgard R, Zaphiropoulos PG, Shimokawa T. Reduction of human embryonal rhabdomyosarcoma tumor growth by inhibition of the hedgehog signaling pathway. Genes Cancer. 2010; 1: 941-951.

107. Pan D, Li Y, Li Z, Wang Y, Wang P, Liang Y. Gli inhibitor GANT61 causes apoptosis in myeloid leukemia cells and acts in synergy with rapamycin. Leuk Res. 2012; 36: 742748. 
108. Zhou J, Wu K, Gao D, Zhu G, Wu D, Wang X, Chen Y, Du Y, Song W, Ma Z, Authement C, Saha D, Hsieh JT, He D. Reciprocal regulation of hypoxia-inducible factor 2alpha and GLI1 expression associated with the radioresistance of renal cell carcinoma. Int J Radiat Oncol Biol Phys. 2014; 90: 942-951. 